from this graph that the corresponding pressure values lie on a line running parallel to a line bisecting the angle formed by the abscissa and the ordinate. All but one of the methods listed in Table II agree within a normal range of about $8 \mathrm{~cm}$. of water, in which connexion the upper limits are more uniform than the lower ones.

To this general measure of agreement between the various methods there is one exception, however, since the values obtained with the method described by Lyons et al. (1938) deviate widely from the findings of the other authors. As the Graph shows, when Lyons's reference point is used the limits should be 5 to $13 \mathrm{~cm}$. of water, and not the 0 to $8 \mathrm{~cm}$. generally employed. Moreover, the lower range-that is, 0 to $3 \mathrm{~cm}$. of water-lies below the tip of the catheter, which would correspond to a negative pressure in the right atrium. This has been contradicted by the results of Richards et al. (1942) and of Cournand et al. (1943), who found a positive mean pressure in the right atrium. False high values for right atrial pressure and right ventricular telediastolic pressure may lead to an erroneous diagnosis of right ventricular failure. In the management of shock false high values may cause the effective blood volume to be overestimated.

\section{Conclusions}

Appraisal of the various reference points and normal ranges used in the determination of the central venous pressure has shown the following:

As shown in our comparative study, after appropriate correction as regards the deviation of the zero point from the tip of the catheter, six of the seven methods investigated agree with one another. A range of $8 \mathrm{~cm}$. of water is considered normal.
The method in which the reference point is taken to be $10 \mathrm{~cm}$. above the surface supporting a horizontal patient yields false high values if the generally used range $(0$ to 8 $\mathrm{cm}$. of water) is adopted.

The selection of the reference point-the distinctive feature of these various methods-is of minor importance. The sole requirement in this respect is that it should be possible to determine the reference point both accurately and easily. Naturally, for purposes of comparison, it would be desirable if a uniform method could be agreed on. The corresponding pressure values yielded by the various methods can be read off from the Chart.

\section{REFERENCES}

Burri, C., and Allgöwer, M. (1967). Schweizerische medizinische Wochenschrift, 97, 1414.

Burri, C., Müller, W., Kuner, E., and Allgöwer, M. (1966). Schweizerische medizinische Wochenschrift, 96, 624.

Cournand, A., et al. (1943). Surgery, 13, 964.

Guyton, A. C., and Greganti, F. P. (1956). American fournal of Physio$\log y, 185,137$.

Hardaway, R. M. (1968). Clinical Management of Shock, p. 163. Springfield, Illinois, Thomas.

Jaikaran, S. M. N., and Sagay, E. (1968). British fournal of Surgery, 55,609

Lyons, R. H., Kennedy, J. A., and Burwell, C. S. (1938). American Heart fournal, 16, 675 .

Mendel, D. (1968). A Practice of Cardiac Catheterisation, p. 222. London, Blackwell Scientific Publications.

Moritz, F., and von Tabora, D. (1910). Deutsches Archiv für klinische Medizin, 98, 475 .

Poppe, H. (1961). Technik der Röntgendiagnostik, 2nd ed., p. 535. Stuttgart, Thieme.

Richards, D. W., Cournand, A., Darling, R. C., Gillespie, W. H., and Baldwin, E. F. (1942). American fournal of Physiology, 136, 115

Weil, M. H., Shubin, H., and Rosoff, L. (1965). Fournal of the American Medical Association, 192, 668.

Wood, P. H. (1956). Diseases of the Heart and Circulation, 2nd ed., p. 188. London, Eyre and Spottiswoode.

\title{
Oral Calcium-loading Test in Rickets and in Neonatal Tetany : Effect of Vitamin D
}

\author{
DAVID G. D. BARR,* M.B., M.R.C.P.ED., D.C.H. ; JOHN O. FORFAR, $†$ M.C., M.D., F.R.C.P.(LOND., ED.), D.C.H.
}

\begin{abstract}
Summary : In an oral calcium-loading test performed $N$ on 10 infants with vitamin-D deficiency rickets and low fasting calcium levels, a comparison of results before and after therapy showed that vitamin $D$ raised the serum calcium level at each stage of the test and altered the response so that a more rapid and substantial rise and fall in serum calcium occurred.

The effects of vitamin $D$ therapy on newborn infants with hypocalcaemic hyperphosphataemic tetany in another study suggests that these infants should be treated in this way to make them more responsive to oral calcium therapy.
\end{abstract}

\section{Introduction}

A calcium-loading test designed to measure the short-term effect of a standard dose of oral calcium on the serum calcium level was previously carried out in idiopathic hypercalcaemia and in a control group of normocalçaemic infants (Barr and Forfar, 1969). In the present study the test was applied to children suffering from vitamin-D-deficiency rickets with a tendency to hypocalcaemia and to infants with hypocalcaemic hyperphosphataemic tetany. The effect of therapeutic dosage of vitamin $\mathrm{D}$ in these two conditions was assessed.

* Senior Registrar, Royal Hospital for Sick Children, Edinburgh 9. † Professor of Child Life and Health, University of Edinburgh.

\section{Patients, Procedures, and Methods}

Of 10 infants with vitamin-D-deficiency rickets, ranging in age from 3 months to 2 years 9 months, five had simple nutritional rickets, two had rickets following extreme prematurity, two had coeliac rickets, and one had rickets after neonatal hepatitis. All these cases were confirmed radiologically and biochemically. None had vitamin-D-resistant rickets.

A control group, in which the normal response in 15 infants aged 2 months to 2 years 6 months had previously been defined (Barr and Forfar, 1969), formed a basis for comparison with the rachitic infants.

Seven patients, aged 6 to 14 days, with hypocalcaemic hyperphosphataemic tetany of the newborn were tested when serum calcium levels were low ; four, aged 13 to 19 days, and one, aged 7 weeks, while recovering on oral calcium supplements and five, aged 14 to 21 days, while recovering on oral calcium supplements together with large doses of vitamin $\mathrm{D}$. The test procedure and methods have been previously described (Barr and Forfar, 1969).

\section{Results}

Control Group.-In the control group the mean values and range have been defined (Barr and Forfar, 1969). The normal 
response was : mean fasting calcium $9.7 \mathrm{mg} . / 100 \mathrm{ml}$., and at one to four hours values of $10.3,10.7,10.5$, and $10.0 \mathrm{mg} . / 100 \mathrm{ml}$. respectively. The ranges based on mean \pm 2 standard deviations were fasting calcium $8.9-10.4 \mathrm{mg} . / 100 \mathrm{ml}$., and at one to four hours $9 \cdot 6-11 \cdot 1,9 \cdot 6-11 \cdot 8,9 \cdot 4-11 \cdot 6$, and $9 \cdot 1-10.8 \mathrm{mg} . / 100$ ml. respectively.

Rickets.-In 10 infants with untreated rickets (Fig. 1) the fasting calcium levels were low (mean $8.1 \mathrm{mg} . / 100 \mathrm{ml}$., range 5.0 to $9.2 \mathrm{mg} . / 100 \mathrm{ml}$.). After the test feed a slow, steady rise in serum calcium level occurred, with peak values at three or four hours in most instances. After a therapeutic course of vitamin $\mathrm{D}$ the same 10 patients were studied again (Fig. 2). Fasting calcium levels had risen (mean $9.6 \mathrm{mg}$. $/ 100 \mathrm{ml}$, range 8.9 to $10.3 \mathrm{mg} . / 100 \mathrm{ml}$.) and the response to the loading test was brisker, with a more substantial rise in calcium levels to peak values within two hours in most instances. In Fig. 3 the curves for untreated rickets, treated rickets, and the control group are related to a common zero point in the fasting state, so that the changes in serum calcium represent increments.

Neonatal Tetany.-Seven patients with neonatal tetany at the onset of the disease had a mean fasting calcium of $6.3 \mathrm{mg} . / 100$ $\mathrm{ml}$. (standard deviation 0.73 ) with an observed range of $5 \cdot 1$ to
7.0. At one to four hours mean values of 6.7 (S.D. 0.72), $7 \cdot 2$ (S.D. 0.82), $7 \cdot 3$ (S.D. 0.81), and 7.3 (S.D. 0.85) mg. $/ 100 \mathrm{ml}$. were obtained. The five patients recovering on oral calcium supplements (Fig. 4) had a mean fasting calcium of $8.5 \mathrm{mg} . /$ $100 \mathrm{ml}$. (range $7 \cdot 8$ to $10 \cdot 1$ ) and a maximal mean rise of 1.8 $\mathrm{mg} . / 100 \mathrm{ml}$. at three hours (range 1.6 to 2.0 ). The five patients recovering on calcium supplements with large dosage of vitamin $\mathrm{D}$ (Fig. 5) had a mean fasting calcium of $8.1 \mathrm{mg} . / 100 \mathrm{ml}$. (range 7.0 to 9.4 ) and a maximal mean rise of $2.7 \mathrm{mg} . / 100 \mathrm{ml}$. at two hours (range 1.7 to 3.9 ). In Fig. 6 the mean curves for tetany in the early stages, during recovery, and with recovery $\overline{0}$ on vitamin $\mathrm{D}$ are related to a common zero point in the fasting state, so that the changes in serum calcium represent increments.

\section{Discussion}

In the rachitic infants the mean inorganic phosphate was $\overrightarrow{\vec{\omega}}$ $3.0 \mathrm{mg} . / 100 \mathrm{ml}$. (range 0.6 to 4.5 ) and the mean alkaline phosphatase 58 K.A. units (range 32 to 114 ) at the time of the initial loading tests. Three infants received vitamin $D$ in a single large intramuscular dosage of $1 \mathrm{mg}$. (40,000 international is
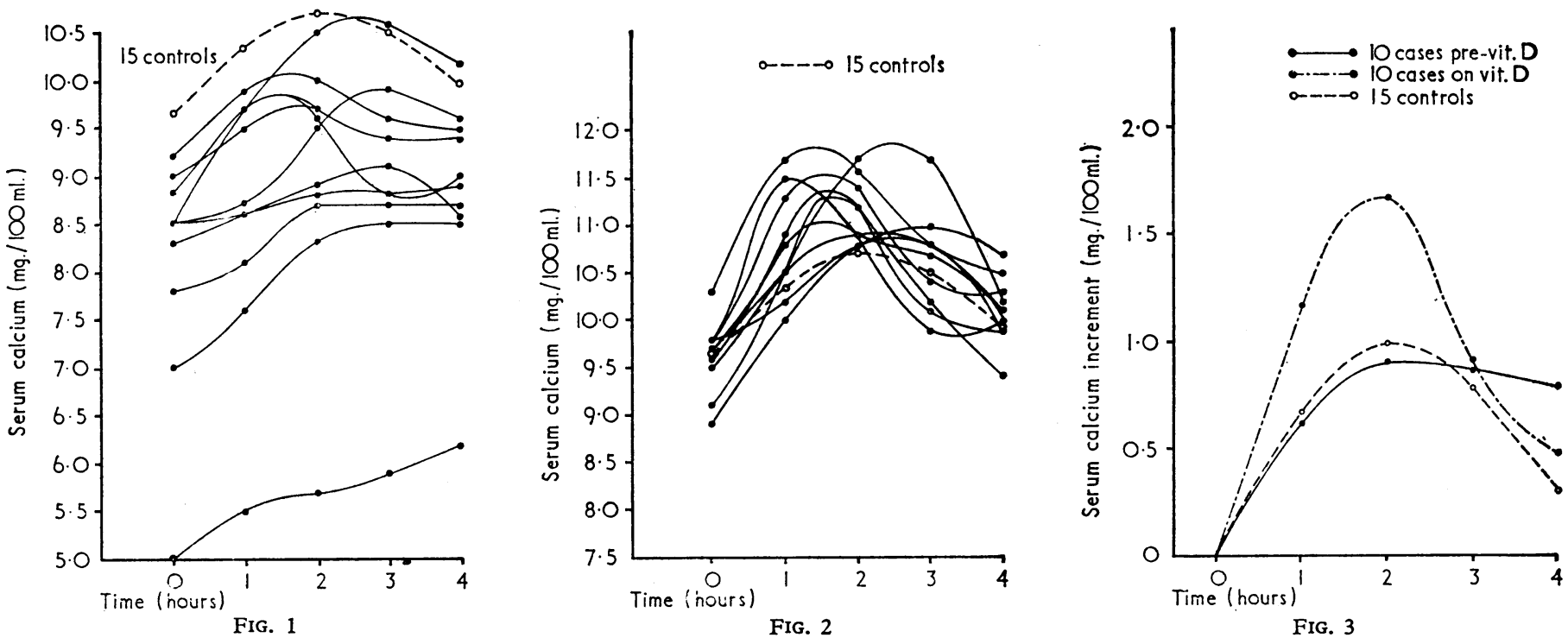

Fig. 1.-Calcium-loading test in rickets; 10 cases before vitamin D. Fig. 2.-Calcium-loading test in rickets; 10 cases on vitamin D. FIG. 3.-Calcium-loading test in rickets.
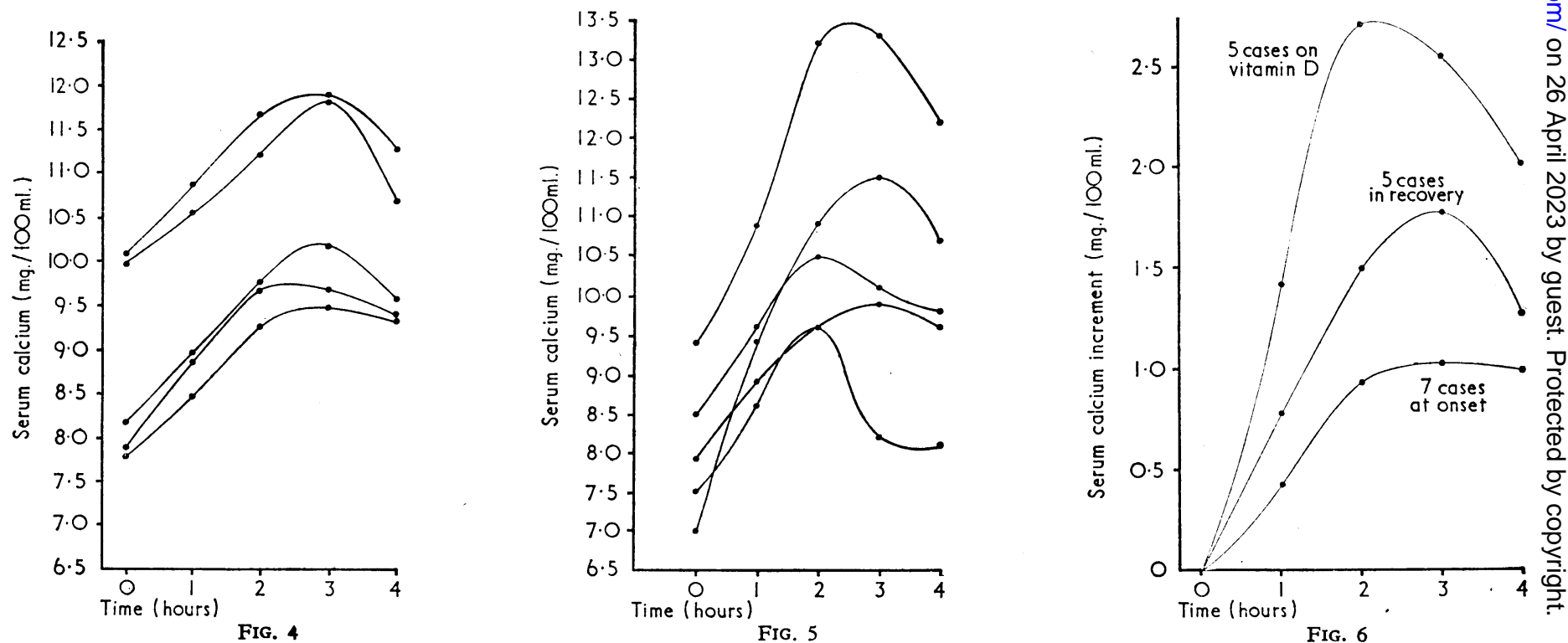

FIG. 4.-Calcium-loading test in neonatal tetany : 5 cases in recovery. Fig. 5.-Calcium-loading test in neonatal tetany; 5 cases in recovery on 
units), $2.5 \mathrm{mg}$., and $10 \mathrm{mg}$. The remainder received oral therapy of 75 to $125 \mu \mathrm{g}$./day for two to three weeks before the second calcium loading test. By that stage the mean inorganic phosphate had risen to $4.5 \mathrm{mg} . / 100 \mathrm{ml}$. (range 1.5 to 6.8 ) and the mean alkaline phosphatase fallen to 46 K.A. units (range 11 to 90). Radiological healing eventually took place in all the patients.

The effect of vitamin-D therapy on the calcium-loading test in rickets can be assessed by the method of paired comparisons (Bradford Hill, 1966). After treatment serum calcium was significantly higher in fasting $(P<0.01)$, one-hour $(P<0.001)$, two-ho'sr $(P<0.001)$, three-hour $(P<0.001)$, and four-hour $(P<0.002)$ specimens. The effect of vitamin $\mathrm{D}$ was clearly shown when the rise in serum calcium was plotted, taking the fasting calcium as zero (Fig. 3). The control group expressed in this way showed $1 \mathrm{mg} . / 100 \mathrm{ml}$. rise at two hours and a fall by four hours. The untreated rachitic infants showed a similar mean rise up to two hours, but a persistently raised level thereafter. Following vitamin-D therapy a change to a pattern of more rapid and substantial rise and fall occurred, and the difference between the mean curves for untreated and treated rachitic infants was significant at one hour $(P<0.001)$ and two hours $(P<0.01)$. The apparently normal response at one and two hours in untreated rachitic infants (Fig. 3) could have been due to the fact that poor calcium absorption was offset by a decreased movement of calcium from the serum, so that the measured rate of rise was no different from normal. Alternatively, calcium absorption might have been normal at the stage of the disease at which the patients were examined.

The persistently raised serum calcium level at two to four hours (Fig. 3) might be explained by a relative imbalance between the absorption of calcium and its transfer from the serum over that period. In rickets vitamin-D administration shifted the calcium-loading curve upwards and to the left, presumably due to its effect in enhancing calcium absorption; with comparable dosage this effect might fail to occur in vitamin-D-resistant rickets where deficient intestinal absorption of calcium may be a basic part of the disorder (Royer et al., 1962 ; Milhaud et al., 1963 ; Lafferty et al., 1964).

The infants with neonatal tetany presented with convulsions at ages ranging from 4 to 10 days. All were of normal birth weight and gestation and had been artificially fed. Furthermore, there were no cases of brain damage, renal failure, or maternal diabetes. Initial phosphate values ranged from $7 \cdot 1$ to $11.4 \mathrm{mg} . / 100 \mathrm{ml}$. All the infants made a complete clinical and biochemical recovery, corresponding to the disorder of transient congenital idiopathic hypoparathyroidism (Fanconi and Prader, 1967).

In the early hypocalcaemic stage the calcium load caused a slow, steady rise in serum calcium to peak values at three to four hours. Normal control infants of this age have not been studied, but the effect of vitamin D can be judged by a comparison between the two recovery groups. These were comparable with regard to sex, birth weight, gestation, feeding, age at presentation, and severity of the initial hypocalcaemia and hyperphosphataemia. Each group received oral calcium gluconate 4-5 g./day and one group received vitamin $D_{2}$ 50-125 $\mu \mathrm{g}$. (2,000 to 5,000 international units) per day to a total dosage of $160-600 \mu \mathrm{g}$. $(6,500$ to 24,000 i.u. $)$ per patient. At the time of the loading test those treated with calcium supplements alone had a mean phosphate of $6.6 \mathrm{mg} . / 100 \mathrm{ml}$. (range 5.7 to 7.5 ), and those also receiving vitamin $\mathrm{D}$ had a mean phosphate of $7.5 \mathrm{mg}$. $/ 100 \mathrm{ml}$. (range 6.4 to 10.4 ). The group on vitamin D showed a greater and more rapid rise in serum calcium than the group recovering on calcium supplements alone (Fig. 6), and the difference between the two mean curves was significant at one hour $(P<0.05)$ and at two hours $(P<0.05)$.

Among the five patients receiving vitamin $\mathrm{D}$ some variation in the test response occurred (Fig. 5). In two patients the response was exaggerated and in one it was identical to that in 3 a patient not receiving extra vitamin $D$. These variations $\mathbb{Q}$ within the group were not obviously a function of the dosage $c$. of vitamin $\mathrm{D}$ or the serum phosphate value. Some infants may $\ddot{\vec{z}}$ be more responsive to vitamin $\mathrm{D}$, and this may represent differ- $\stackrel{\oplus}{\rightarrow}$ ences in absorption, metabolism, or biological activity of the vitamin $\mathrm{D}$ or be related to some other unidentified factor. On average, however, the infants receiving vitamin $\mathrm{D}$ were more responsive to oral calcium, presumably as a result of more $\stackrel{\square}{\varnothing}$ efficient calcium absorption.

In the normal infant vitamin D given in physiological dosage $\vec{\nabla}$ during the first week of life may aggravate hypocalcaemia and hyperphosphataemia (Gittleman and Pincus, 1951; Pincus $\vec{\omega}$ et al., 1954), but in older infants with hypocalcaemia thera- $\frac{D}{\circ}$ peutic dosage may act differently. Nelson (1964) and Wilkins 3 (1965) state that in transient neonatal tetany vitamin $\mathrm{D}$ is $\dot{\omega}$ ineffective, and Fourman and Royer (1968) consider it unneces- ir sary and even dangerous, though recommending 10,000 i.u./day for infantile hypoparathyroidism. As the transient form of disturbance may last weeks or months, and as it is indistinguish- $f$ able at onset from chronic hypoparathyroidism, it would seem 은 not unreasonable to adopt a similar therapeutic regimen. Such an approach was used by Fanconi and Prader (1967), who $\overrightarrow{0}$ achieved an apparently satisfactory response in seven cases of transient hypoparathyroidism with pharmacological doses of vitamin $\mathrm{D}$ or be related to some other unidentified factor. On $\vec{\emptyset}$
hypoparathyroidism in older patients.

The present study would support the use of vitamin D-O for example, $125 \mu \mathrm{g}$. or $5,000 \mathrm{i} . u$./day-in hypocalcaemic/ hyperphosphataemic tetany of the newborn.

We acknowledge the helpful co-operation of the paediatricians $\overrightarrow{\vec{D}}$ of the Royal Hospital for Sick Children and the Northern Group 3 Hospitals, Edinburgh, in allowing us to study patients under their $\bar{T}$ care. Mr. Shepley, of the department of medical illustration, University of Edinburgh, kindly drew the graphs.

Requests for reprints should be sent to D. G. D. Barr, Royal Hospital for Sick Children, Sciennes Road, Edinburgh 9.

REFERENCES

Barr, D. G. D., and Forfar, J. O. (1969). British Medical fournal, $1, \frac{2}{2}$ Hill, A. B. (1966). Principles of Medical Statistics, 8th ed., p. 149.N London, Lancet Ltd.

Fanconi, A., and Prader, A. (1967). Helvetica Paediatrica Acta, 22, 342. $\frac{D}{\mathrm{O}}$ Fourman, P., and Royer, P. (1968). Calcium Metabolism and the Bone, 2nd ed., pp. 210, 339. Oxford, Blackwell.

Gittleman, I. F., and Pincus, J. B. (1951). Pediatrics, 8, 778.

Lafferty, F. W., Herndon, C. H., and Pearson, O. H. (1964). In Dynamic CW Studies of Metabolic Bone Disease, edited by $\mathrm{O}$. $\mathrm{H}$. Pearson and G. F. Joplin, p. 163. Oxford, Blackwell.

Milhaud, G., Job, J. C., and Gentil, C. (1963). Revue Française d'Etudes Cliniques et Biologiques, 8, 179.

Nelson, W. E. (1964). Textbook of Pediatrics, 8th ed., p. 391. Philadelphia, Saunders.

Pincus, J. B., Gittleman, I. F., Sobel, A. E., and Schmerzler, E. (1954). Pediatrics, 13, 178 .

Royer, P., Mathicu, H., and Gerbeaux, S. (1962). Rein et Foie, 4, 37.

Wilkins, L. (1965). The Diagnosis and Treatment of Endocrine Dis-@ orders in Childhood and Adolescence, 3rd ed., p. 491. Springfield, Thomas. 